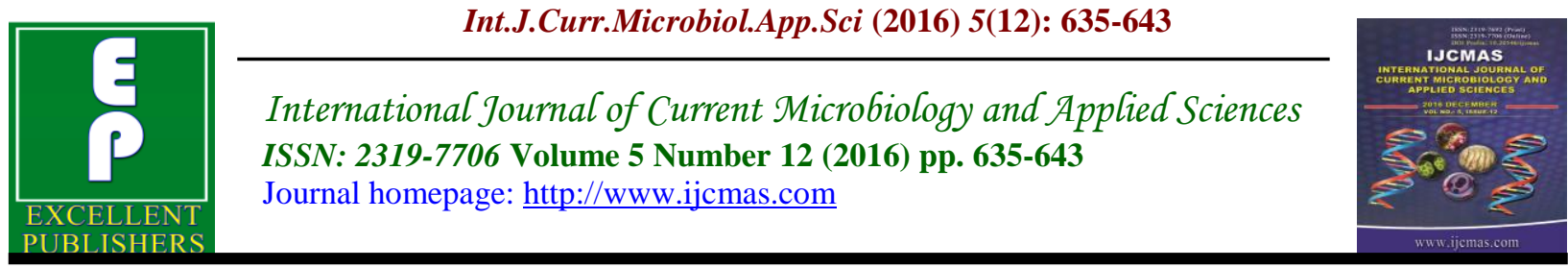

Original Research Article

http://dx.doi.org/10.20546/ijcmas.2016.512.070

\title{
In vitro Effect of Various Plant Growth Regulator on Micro Propagation of Celastrus paniculatus: An Important Medicinal Plant
}

\author{
Rahul Vijay*, Jyoti Shukla and Rajesh Saxena \\ Madhya Pradesh Council of Science and Technology, Bhopal (M.P), India \\ *Corresponding author
}

Keywords

Celastrus paniculatus, Micropropagation, Medicinal Plants, Plant Tissue Culture.

\section{Article Info}

Accepted:

20 November 2016

Available Online:

10 December 2016

\section{A B S T R A C T}

In-vitro effect of various growth regulators on propagation of Celastrus paniculatus, a medicinally herbs of India was observed in this study. C. paniculatus has been used in the various ancient traditional system of medicine and having a very poor seed germination percentage. Healthy nodal segments of the herb was used as explants with basic MS medium for shoot initiation and multiplication containing various combinations of different growth regulators. MS full and ${ }^{1 / 2} \mathrm{MS}$ were used for rooting of plantlets with 25 to $200 \mathrm{mg} / \mathrm{l}$ Activated Charcoal (AC). Maximum mean number of initiated plantlets $1.8 \pm 0.42$ with mean length $4.6 \pm 1.34$ were found in MS medium treated with lowest concentration of BA, while maximum mean number of multiplied plantlets $21.7 \pm 1.25$ with mean length $6.8 \pm 0.91$ were found in MS medium treated with $4.44 \mu \mathrm{M}$. Maximum mean number of roods $16.2 \pm 0.78$ with Mean length $9.19 \pm 0.68$ was observed on ${ }^{1 / 2} \mathrm{MS}$ medium with $100 \mathrm{mg} / \mathrm{l}$ activated charcoal. The rooted plantlets were successfully hardened in 1:1:1 ratio of sand: soil: vermicompost and successfully established in soil.

\section{Introduction}

Celastrus paniculatus Willd.(family Celastraceae) also called 'Jyotishmati' in Sanskrit or 'Malkangani'and 'Duhudu'in Hindi improves memory and cognitive functions. It is widely used in ayurvedic system of medicine and beneficial in neurological diseases and pain disorders including muscle cramps, backache, sciatica, osteoarthritis, facial paralysis and paralysis. This plant is used in cure many diseases such as leprosy, leucoderma, skin diseases, paralysis, depression, arthritis, asthma and fever (Bhanumathy et al., 2010; Kumar and Gupta, 2002; Godkar et al., 2006; Godkar, et al., 2003; Patil et al., 2010; Sharma et al., 2001). C. paniculatus Seeds contains around $30 \%$ oil content in which many alkaloids like Celapagin, Celapanigin, Celapanin, Celastrine, Paniculatine, etc. are present. Seeds and its oil are mainly used in ayurvedic medicines. Leaves are also used for de-addiction. Generally, leaf juice is beneficial for treating opium addiction. This species distributed in, India (widespread), Nepal, Sri Lanka, Myanmar, Bhutan, Thailand, Vietnam, Laos, Java, Malaysia, Sumatra, Philippines, Moluccas, China, Taiwan (Hassler, 2016). 
Propagation of $C$. paniculatus by seeds is very poor owing to inhibitory compounds present in the seed coat, and the percentage seed germination is very low. Rooting of cuttings is also not successful (De Silva and Senarath). The theoretical basis for plant tissue culture was proposed by Gottlieb Haberlandt, German Academy of science in 1902 on his experiments on the culture of single cell. The first true cultures were obtained by Gautheret from cambial tissue of Acer pseudoplatanus. The term plant tissue culture (Micro propagation) is generally used for the aseptic culture of cells, tissues, organs and their components under defined chemical and physical conditions in vitro. Today Micro propagation method of plant tissue culture was widely used for conservation and mass production of endangered and economically important plant species. Some researchers work on the microporpagation of $C$. Paniculatus through callus (Sharada et al., 2003) and through bud differentiation (Rao and Purohit, 2006) with limited success. Consequently, an attempt was made for propagate the $C$. paniculatus through micro propagation and to establish tissue cultured plants in the green house successfully.

\section{Materials and Methods}

\section{Collection of explant}

Branches of $C$. Paniculatus were collected from healthy growing plants from medicinal garden of Prof.T.S.Murthi Science and Technology Station Obedullaganj, Raisen (M.P.)

\section{Sterilization of Explant}

Nodal explants were cut and washed in running tap water to remove the superficial dust particles and mud adhering to its surface. Explants were washed with sevelon
(3-4 drops/100ml) in a vial by gentle agitating conditions. The explants were thoroughly rinsed with distilled water for several times. Again these explants were dipped in to the $1 \%$ fungicide (Bavistin) treatment was given for 15 minutes and then washed with distilled water. For surface sterilization. Explants were transferred to sterile empty flasks under aseptic conditions and given a quick dip in $70 \%$ alcohol and subsequently they were washed in distilled water. After that, the explants were surface sterilized with different concentration of sterile $\left(\mathrm{HgCl}_{2}\right)$ for different duration as per the treatment to find out the best treatment for sterilization of explants. To remove the traces of sterile explants were washed in sterilized distilled water at least 5-6 times. The procedure was carried out in the inoculation chamber under laminar air flow hood.

\section{Preparation of MS Medium}

Culture media was prepared as per described method of Murashig and Skoog (1962) and different growth regulator was added as per requirement. For the initiation of ex-plant various concentration of $\mathrm{BA}(0.44$ to 2.22 $\mu \mathrm{M})$ alone and with IA $(0.57$ to $1.71 \mu \mathrm{M})$ and NA $(0.54$ to $1.61 \mu \mathrm{M})$ were used, while concentration of BA $(2.22$ to $11.1 \mu \mathrm{M})$ alone and IA $(0.57$ to $1.71 \mu \mathrm{M})$ and NA $(0.54$ to $1.61 \mu \mathrm{M})$ with BA (2.22 to $6.66 \mu \mathrm{M})$ were used for multiplication. MS full and 1/2MS were used for rooting of plantlets with 25 to $200 \mathrm{mg} / \mathrm{l}$ Activated Charcoal (AC) combination adding $30 \mathrm{~g} / \mathrm{l}$ sucrose and $5.7 \%$ agar. The hormones used for experiment were taken from stock solutions, which were previously prepared and kept under cold condition in refrigerator (Doods and Roberts, 1985). The $\mathrm{pH}$ of the medium was adjusted to 5.7 with $0.1 \mathrm{NaOH}$ before autoclaving at $15 \mathrm{lbs}$ and $121^{\circ} \mathrm{C}$ for $18 \mathrm{~min}$. 


\section{Aseptic Inoculation of Explant}

Nodal segments about 0.5-0.8 cm were prepared aseptically and were implanted vertically on Surface disinfected nodal explants were inoculated onto full strength MS medium (Murashige and Skoog, 1962) fortified with specific concentrations of growth regulators. The cultures were incubated at a constant temperature of $26 \pm 2^{\circ} \mathrm{C}$ with $16 \pm 1 \mathrm{~h}$ photoperiod (3000 lux).

\section{Results and Discussion}

\section{Surface Sterilization and Induction of Axillary Shoots}

Treatment of explants with $0.1 \% \mathrm{HgCl}_{2}$ for 3 minutes resulted $100 \%$ contamination-free viable cultures. Final observation after 3-4 weeks showed that MS media supplemented with $0.44 \mu \mathrm{M} \mathrm{mg} / \mathrm{l}$ of BA proved to be most capability in shoot induction. On this medium an average of $1.8 \pm 0.42$ shoots with mean shoot length $4.6 \pm 1.34 \mathrm{~cm}$ were obtained (table 1, figure 1A and 2).

\section{Shoot Multiplication}

Shoot multiplication is depend on different concentration of plant growth regulators. Sometimes BA increasing is best for shoot or just opposite. Activated auxiliary shoots from the nodal explants and transfer to fresh medium containing $\mathrm{BA}$ alone and combination of BA with NA and IA to establish a stock of shoots used for in vitro multiplication. When we look Results in the present study showed the essential of plant growth regulators for in vitro multiplication, as the shoots cultured on basal medium did not multiply and become dead. BA at a concentration of $4.44 \mu \mathrm{M}$ just gave an average of $21.7 \pm 1.25$ shoots with mean shoot length $6.8 \pm 0.91 \mathrm{~cm}$ after $3-4$ weeks of culture (table 2, figure $1 \mathrm{~B}$ and 3 ).
Increasing the concentration of BA to 4.44 $\mu \mathrm{M}$, a decrease in shoot multiplication rate was observed. However, comparative number, length and health of shoots on media with BA + IA/NA were not good. De Silva and Senarath (2009) was observed that MS medium supplemented $10.0 \mu \mathrm{M}$ BAP and $14.0 \mu \mathrm{M}$ IAA produced maximum multiple shoots. They induced Multiple shoots in the MS media with $5.0 \mu \mathrm{M}$ BAP and $0.5 \mu \mathrm{M}$ IAA. Arya et al. (2002) reported multiplication in a medium containing NAA and BA. Martin et al., (2006) achieved Maximum shoot induction (five shoots per explant) in MS medium supplemented with $1.5 \mathrm{mg} \mathrm{1-1} \mathrm{BA}$ and $0.1 \mathrm{mg} \mathrm{1-1} \mathrm{NAA.} \mathrm{Lal}$ and Singh (2010) found the maximum number of shoots $(8.9 \pm 0.5)$ along with hundred per cent bud break in the MS medium supplemented with $1.0 \mathrm{mgl}-1 \mathrm{BAP}$. Senapati et al (2013) observed that the Murashige and Skoog (MS) basal medium supplemented with $0.5 \quad \mathrm{mg} / \mathrm{L} \quad 6-$ benzylaminopurine (BAP) and $0.1 \mathrm{mg} / \mathrm{L}$ naphthalene acetic acid (NAA) showed maximum percentage of shoot multiplication $(83.4 \%)$ with 8.2 shoots/explants.

\section{In vitro Rooting}

After 30 Days of growth, rooting growth is rarely increase day by day in best culture. The multiple-shoot clumps produced on this medium were transferred to solidified MS growth-regulator-free medium for shoot elongation and rooting. On opposite, shoots were also observed for rooting on full or half-strength MS medium with Activated Charcol ensuing excellent response for root induction. Maximum rooting was recorded in medium containing $100 \mathrm{mg} / \mathrm{l}$ Activated Charcol Supplemented with $1 / 2$ MS medium (figure 1C). On this medium an average of $16.2 \pm 0.78$ roots with average root length $9.19 \pm 0.68 \mathrm{~cm}$ was observed after 3-4 weeks (table 3 , figure 4). 
Table.1 Effect of plant growth regulators on in vitro auxiliary shoot induction in Celastrus paniculatus

\begin{tabular}{cccccc}
\hline SL & \multicolumn{2}{c}{ MS + PGR $(\boldsymbol{\mu M})$} & \multicolumn{2}{c}{ Observations after 25 days } \\
\cline { 2 - 6 } & BAP & IAA & NAA & $\begin{array}{c}\text { Mean shoot } \\
\text { number }\end{array}$ & $\begin{array}{c}\text { Mean shoot } \\
\text { length }(\mathbf{c m})\end{array}$ \\
\hline 1. & 0 & 0 & 0 & $0.2 \pm 0.42$ & $0.7 \pm 1.49$ \\
2. & $0.44 \mu \mathrm{M}$ & 0 & 0 & $1.8 \pm 0.42$ & $4.6 \pm 1.34$ \\
3. & $0.88 \mu \mathrm{M}$ & 0 & 0 & $0.8 \pm 0.78$ & $2 \pm 1.76$ \\
4. & $1.33 \mu \mathrm{M}$ & 0 & 0 & $0.7 \pm 0.70$ & $1.8 \pm 1.68$ \\
5. & $1.77 \mu \mathrm{M}$ & 0 & 0 & $0.5 \pm 0.70$ & $1.3 \pm 1.76$ \\
6. & $2.22 \mu \mathrm{M}$ & 0 & 0 & $0.4 \pm 0.69$ & $1.1 \pm 1.79$ \\
7. & $0.44 \mu \mathrm{M}$ & $0.57 \mu \mathrm{M}$ & 0 & $0.4 \pm 0.51$ & $1.5 \pm 1.95$ \\
8. & $0.88 \mu \mathrm{M}$ & $1.14 \mu \mathrm{M}$ & 0 & $0.7 \pm 0.82$ & $1.4 \pm 1.50$ \\
9. & $1.33 \mu \mathrm{M}$ & $1.71 \mu \mathrm{M}$ & 0 & $0.8 \pm 0.91$ & $1.3 \pm 1.41$ \\
10. & $0.44 \mu \mathrm{M}$ & 0 & $0.54 \mu \mathrm{M}$ & $1 \pm 0.94$ & $2.1 \pm 1.91$ \\
11. & $0.88 \mu \mathrm{M}$ & 0 & $1.07 \mu \mathrm{M}$ & $0.8 \pm 0.91$ & $1.7 \pm 1.88$ \\
12. & $1.33 \mu \mathrm{M}$ & 0 & $1.61 \mu \mathrm{M}$ & $0.9 \pm 0.87$ & $1.2 \pm 1.03$ \\
\hline
\end{tabular}

Note: Each treatment consisted of 10 replications. Data (Mean \pm SE) were recorded after 20 days of culture.

Table.2 Effect of plant growth regulators on in vitro axillary shoot multiplication in Celastrus paniculatus

\begin{tabular}{cccccc}
\hline & \multicolumn{2}{c}{ MS + PGR $(\boldsymbol{\mu M})$} & \multicolumn{2}{c}{ Observations after 25 days } \\
\cline { 2 - 6 } SL & BAP & IAA & NAA & Mean shoot number & $\begin{array}{c}\text { Mean shoot length } \\
\text { (cm) }\end{array}$ \\
\hline 1. & 0 & 0 & 0 & $3.7 \pm 0.67$ & $3.6 \pm 0.69$ \\
2. & $2.22 \mu \mathrm{M}$ & 0 & 0 & $17.6 \pm 1.50$ & $4.7 \pm 0.82$ \\
3. & $4.44 \mu \mathrm{M}$ & 0 & 0 & $21.7 \pm 1.25$ & $6.8 \pm 0.91$ \\
4. & $6.66 \mu \mathrm{M}$ & 0 & 0 & $19.1 \pm 1.66$ & $4.7 \pm 0.94$ \\
5. & $8.88 \mu \mathrm{M}$ & 0 & 0 & $15.3 \pm 1.56$ & $3.7 \pm 0.63$ \\
6. & $11.1 \mu \mathrm{M}$ & 0 & 0 & $14.2 \pm 1.39$ & $3.4 \pm 0.51$ \\
7. & $2.22 \mu \mathrm{M}$ & $0.57 \mu \mathrm{M}$ & 0 & $11.9 \pm 1.28$ & $4.1 \pm 0.73$ \\
8. & $4.44 \mu \mathrm{M}$ & $1.14 \mu \mathrm{M}$ & 0 & $11.1 \pm 1.19$ & $3.9 \pm 0.56$ \\
9. & $6.66 \mu \mathrm{M}$ & $1.71 \mu \mathrm{M}$ & 0 & $10.5 \pm 1.26$ & $3.3 \pm 0.67$ \\
10. & $2.22 \mu \mathrm{M}$ & 0 & $0.54 \mu \mathrm{M}$ & $12.3 \pm 1.33$ & $4.6 \pm 0.84$ \\
11. & $4.44 \mu \mathrm{M}$ & 0 & $1.07 \mu \mathrm{M}$ & $11.2 \pm 0.91$ & $4.4 \pm 0.84$ \\
12. & $6.66 \mu \mathrm{M}$ & 0 & $1.61 \mu \mathrm{M}$ & $10.7 \pm 0.94$ & $3.6 \pm 0.699$ \\
\hline
\end{tabular}

Note: Each Treatment consisted of 10 replications. Data (MEAN \pm SE) were recorded after 20 days of culture. 
Table.3 Rooting response of in vitro regeneration excised shoots (10 repeats).

\begin{tabular}{|c|c|c|c|}
\hline SL & Medium & $\begin{array}{c}\text { Activated charcoal } \\
(\mathrm{mg} / \mathrm{l})\end{array}$ & $\begin{array}{c}\text { No. of roots/ Plantlets } \\
\text { (Mean_SE) }\end{array}$ \\
\hline 1. & -- & -- & $4.2 \pm 0.42$ \\
\hline 2. & MS & -- & $6.3 \pm 0.94$ \\
\hline 3. & ${ }^{1 / 2} \mathrm{MS}$ & -- & $6.7 \pm 0.67$ \\
\hline 4. & 1/2 MS & 25 & $7.7 \pm 0.82$ \\
\hline 5. & ${ }^{1 / 2} \mathrm{MS}$ & 50 & $9.1 \pm 0.87$ \\
\hline 6. & ${ }^{1 / 2} \mathrm{MS}$ & 100 & $16.2 \pm 0.78$ \\
\hline 7. & ${ }^{1 / 2} \mathrm{MS}$ & 125 & $12.7 \pm 0.82$ \\
\hline 8. & ${ }^{1 / 2} \mathrm{MS}$ & 150 & $9.2 \pm 0.0 .78$ \\
\hline 9. & ${ }^{1 / 2} \mathrm{MS}$ & 200 & $7.1 \pm 0.87$ \\
\hline
\end{tabular}

Note: Each treatment consisted of 10 replications. Data (Mean \pm SE) were recorded after 20 days of culture.

Fig.1 Micropropagation of Celastrus paniculatus.
A.Initiation
B. Multiplication
C. Rooting

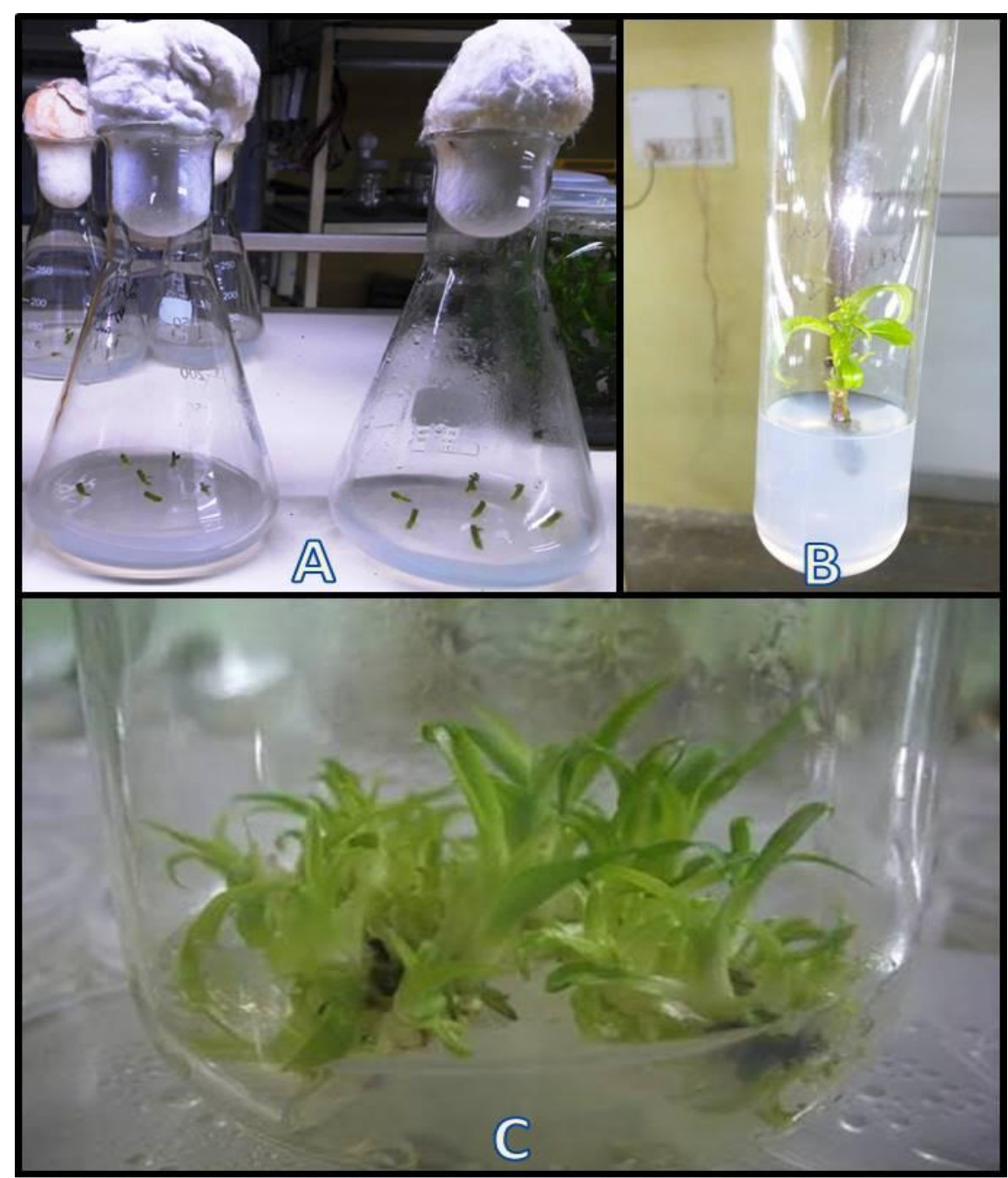


Fig.2 Effect of plant growth regulators on in vitro auxiliary shoot induction in Celastrus paniculatus

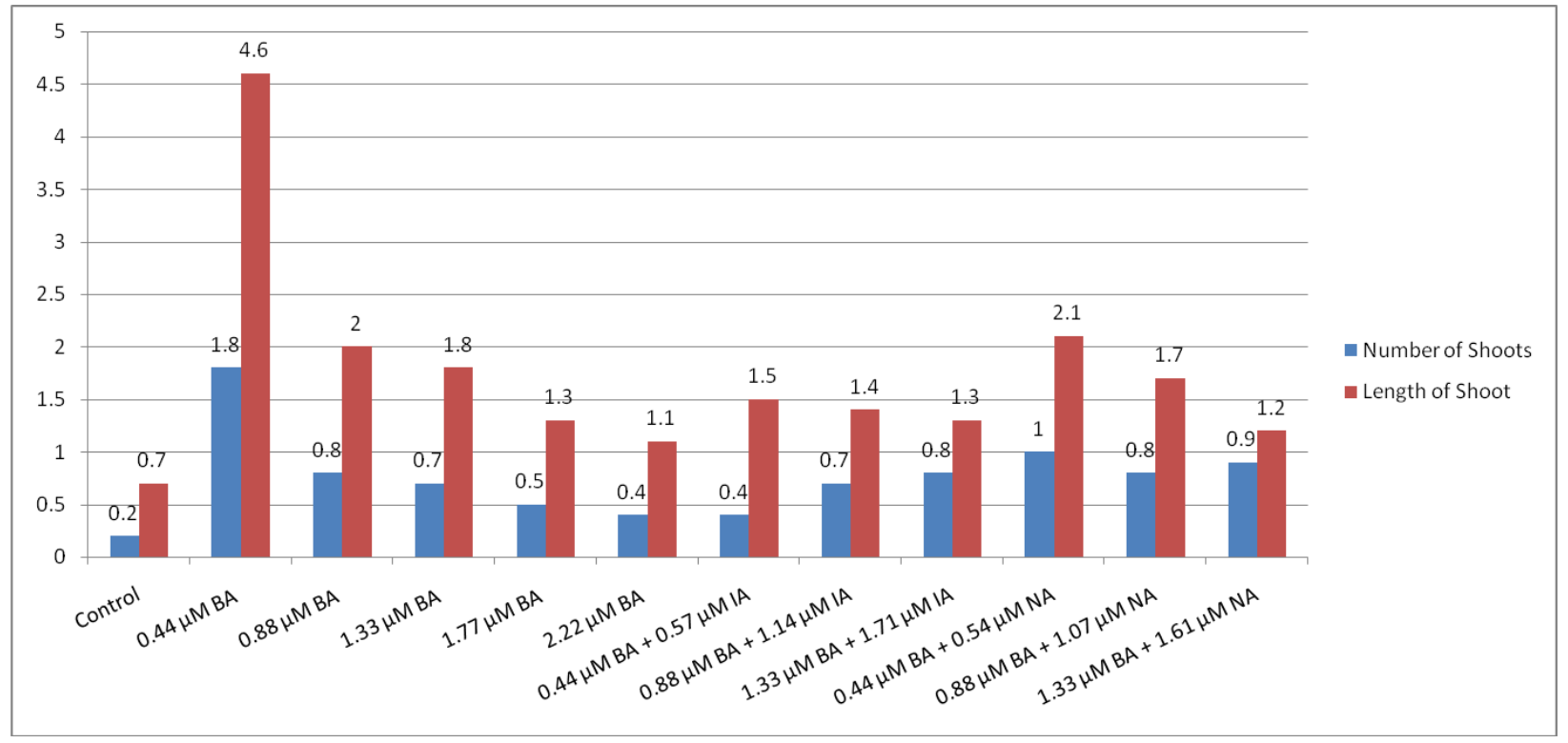

Fig.3 Effect of plant growth regulators on in vitro axillary shoot multiplication in Celastrus paniculatus

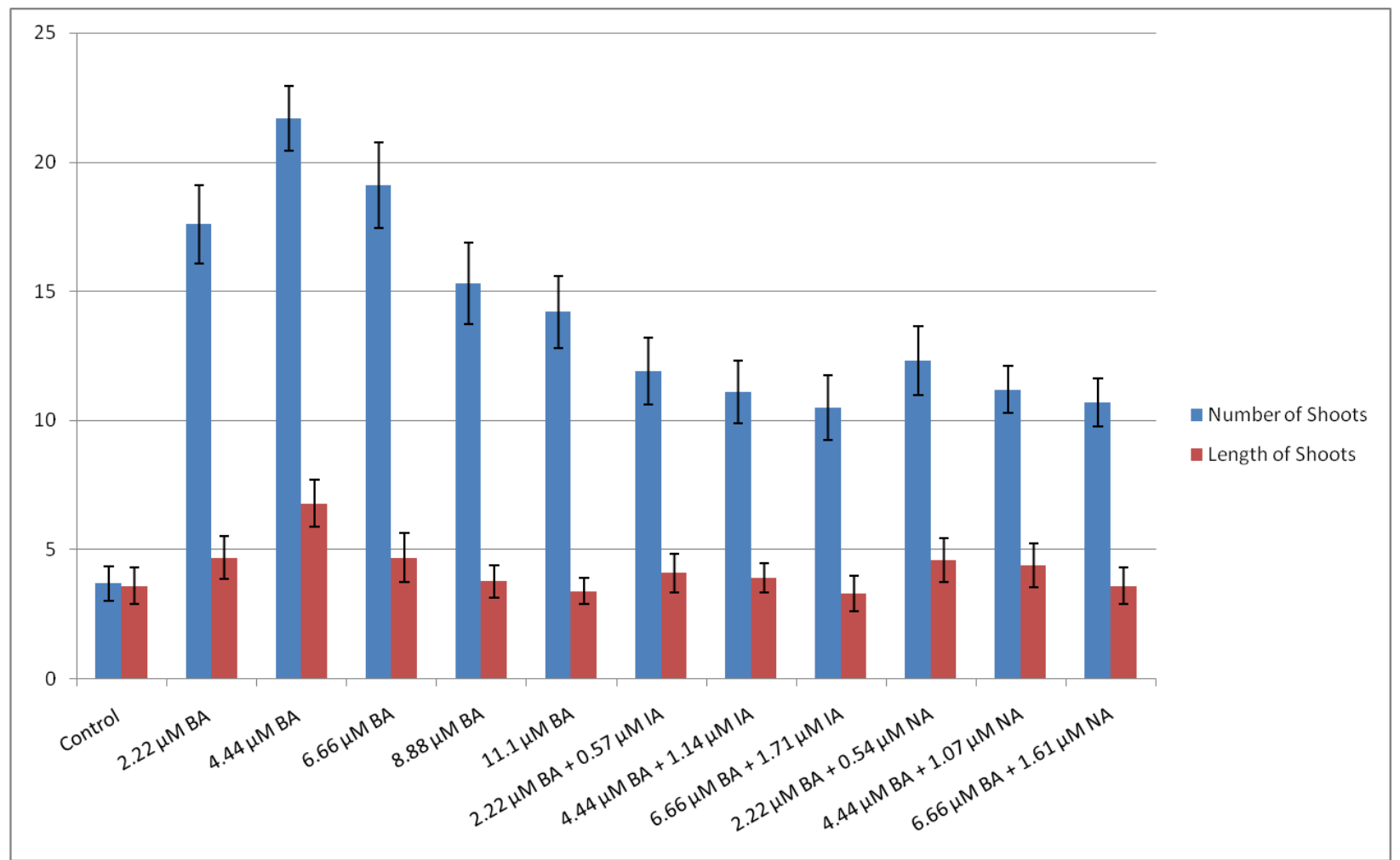


Fig.4 Rooting response of in vitro regeneration excised shoots (10 repeats).

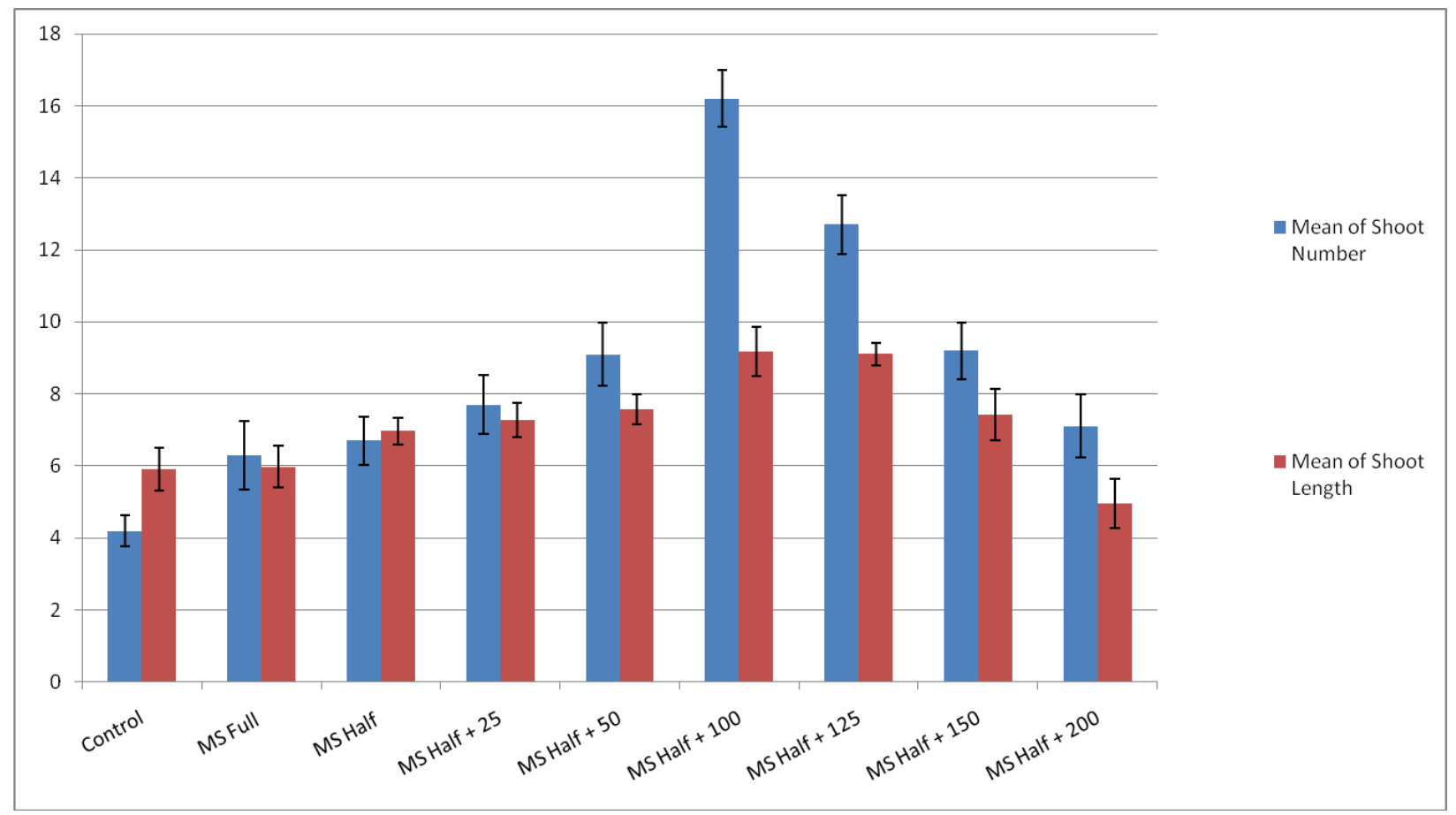

De Silva and Senarath (2009) found good rooting on elongated shoots and the highest rooting percentage $(73.3 \%)$ in the MS medium supplemented with $5.6 \mu \mathrm{M}$ IAA and $9.6 \mu \mathrm{M}$ Indole-3-butyric acid (IBA). Martin et al., (2006) reported that the shoots that were pulse-treated in a solution of 100 mg $1-1$ each of IBA and NOA for $2 \mathrm{~h}$ and then for $3 \mathrm{~min}$ in $10 \mathrm{mg} \mathrm{l}-1$ chlorogenic acid gave $90 \%$ rooting Two to three roots of $2-4$ $\mathrm{cm}$ in length were produced within a period of 5 weeks. Lal and Singh (2010) proved that the MS half strength medium supplemented with $0.5 \mathrm{mgl}-1$ NAA best with hundred per cent rooting. Senapati $e t$ al., (2013) was achieved Maximum rooting of $73.3 \%$ with 4.8 roots $/$ shoot on halfstrength MS media supplemented with 0.5 $\mathrm{mg} / \mathrm{L}$ indole-3-acetic acid (IAA) and the percentage of survival was $91 \%$ after acclimatization.

Various studies showed that the positive effect of NAA at lower concentrations during rooting in various medicinal plants like Verbascum thapsus (Turker et al., 2001) and Santolina canescens (Casado et al., 2002). Peeters et al. (1991) reported that NAA was taken up six times faster than IAA and Van der Krieken et al., (1993) confirmed that IBA was taken up four times faster than IAA.

In conclusion, $C$. Paniculatus has always been a topic of interest of researchers. From tissue culture point of view several studies have been performed to propagate the plant in vitro. The highlights of the study are Use of low concentration of plant growth regulators and minimization of time required for field transfer of tissue culture raised plantlets. Free plants produced open the scope for utilization of plant material for antimicrobial testing and suitable pharmaceutical preparations. Apart from this in vitro propagation of $C$. paniculatus showed a highest rate of multiplication which cannot be seen in naturally found species of $C$. paniculatus The Malkangani research will give a new insight of research 
in medicinal components of plants through various advance techniques.

\section{Acknowledgement}

The authors wish to thank Prof. P. K. Verma, Director General of MPCST for their help and encouragement during the work.

\section{References}

Arya, V., Singh, R.P., Shekhawat, N.S. 2002. A micropropagation protocol for mass multiplication and off-site conservation of Celastrus paniculatus - a vulnerable medicinal plant of India. J. Sustain Forest, 14: 107-120.

Bhanumathy, M., Harish, M.S., Shivaprasad, H.N., Sushma, G. 2010. Nootropic activity of Celastrus paniculatus seed. Pharm. Biol., 48(3): 324-7.

Casado, J.P., Navarro, M.C., Utrilla, M.P., Martinez, A., Jimenez, J. 2002. Micropropagation of Santolina canescens Lagasca and in vitro volatiles production by shoot explants. Plant Cell Tissue Organ. Cult., 69: 147-153.

De Silva, M.A.N., Senarath, W.T.P.S.K. 2009. Development of a Successful Protocol for in vitro Mass Propagation of Celastrus paniculatus Willd. - A Valuable Medicinal Plant. Trop. Agri. Res., 21(1): 21 - 29.

Godkar, P.B., Gordon, R.K., Ravindran, A., Doctor, B.P. 2003. Celastrus paniculatus seed water soluble extracts protect cultured rat forebrain neuronal cells from hydrogen peroxide-induced oxidative injury. Fitoterapia, 74(7-8): 658-69.

Godkar, P.B., Gordon, R.K., Ravindran, A., Doctor, B.P. 2006. Celastrus paniculatus seed oil and organic extracts attenuate hydrogen peroxide- and glutamate-induced injury in embryonic rat forebrain neuronal cells. Phytomedicine, 13(1-2):29-36. Epub 2005 Jun 28.

Kumar, M.H., Gupta, Y.K. 2002. Antioxidant property of Celastrus paniculatus willd.: a possible mechanism in enhancing cognition. Phytomedicine, 9(4):302-11.

Lal, D., Singh, N. 2010. Mass multiplication of Celastrus paniculatus Wild: An important medicinal plant under in vitro conditions via nodal segments. Int. J. Biodiv. Conserv., 2: 140-145.

Martin, G., S.P. Geetha, Sudhakar, S., Raghu, R.A.V., Balachandran, I., Ravindran, P.N. 2006. An effi cient micropropagation system for Celastrus paniculatus Willd.: a vulnerable medicinal plant. J. For. Res., 11:461465.

Patil, R.H., Prakash, K., Maheshwari, V.L. 2010. Hypolipidemic Effect of Celastrus paniculatus in Experimentally Induced Hypercholesterolemic Wistar Rats Indian J Clin Biochem., 25(4): 405410.

Peeters, A.J.M., Gerads, W., Barendse, G.W.M., Wullems, G.J. 1991. In vitro flower bud formation in tobacco: interaction of hormones. Plant Physiol., 97: 402-408.

Rao, M.S., Purohit, S.D. 2006. In vitro shoot bud differentiation and plantlet regeneration in Celastrus paniculatus Willd. J. Biol. Planta., 50(4): 501 506.

Rout, G.R., Mahato, A. \& Senapati, S.K. 2008. In vitro clonal propagation of Nyctanthes arbortristis. Biol. Plant, 52: 521- 524.

Senapati, S.K., S. Aparajita, G.R. Rout. 2013. Micropropagation and assessment of genetic stability in Celastrus paniculatus: An endangered 
medicinal plant. Biologia, 68(4) 627632.

Sharada, M., Ashok, A., Kaul, M.K. 2003. Regeneration of plantlets via callus cultures in Celastrus paniculatus Willd. - A rare endangered medicinal plant. J. Biochem. And Biotec., 12: 65 $-69$.

Sharma, P.C., Yelne, M.B., Dennis, T.J. 2001. Database on Medicinal Plants used in Ayurveda. Vol. 2, Central Council for Research in Ayurveda and Sidda. Janakpori, New Delhi.
Turker, A.U., Camper, N.D., Gurel, E. 2001. In vitro culture of common mullein (Verbascum thapsus L.). In Vitro Cell Dev. Biol. Plant. 37: 40-43.

Van der Krieken, W.M., Breteler, H., Visser, M.H.M., Mavridou, D. 1993. The role of conversion of IBA into IAA on root regeneration in apple: introduction of a test system. Plant Cell Rep., 12: 203206.

Walia, N., Sinha, S. \& Babbar, S.B. 2003. Micropropagation of Crataeva nurvala. Biol. Plant., 46: 181-185.

\section{How to cite this article:}

Rahul Vijay, Jyoti Shukla and Rajesh Saxena. 2016. In vitro Effect of Various Plant Growth Regulator on Micro Propagation of Celastrus paniculatus: An Important Medicinal Plant. Int.J.Curr.Microbiol.App.Sci. 5(12): 635-643. doi: http://dx.doi.org/10.20546/ijcmas.2016.512.070 